\title{
ECONOMIC ASPECTS OF THE PROCESSING OF VEGETABLE PLANTS
}

\author{
András Palkovics*, Kata Hiri, Adrienn Szilágyi, Attila Nagy, Fanni Jójárt \\ Faculty of Horticulture and Rural development, John von Neumann University, Kecskemét, Mészöly Gy. sqr. \\ 1-3., Hungary \\ https://doi.org/10.47833/2020.2.AGR.012
}

\author{
Keywords: \\ vegetable plant processing \\ by-product \\ vegetable peel \\ abrasive peeling
}

\section{Article history:}

Received

Revised

Accepted

10 Nov 2019

26 Feb 2020

10 March 2020

\begin{abstract}
Among the vegetable plants, carrots, parsley roots, onions, garlic and celery are the most popular ones in the Hungarian cuisine. Valueless by-product is produced in large quantities during the processing, in particular the peeling of these vegetables. Depending on the type of peeling the by-product can be 15-40\% of the unpeeled raw material. The waste management of byproducts from food processing make a major problem in Europe.
\end{abstract}

\section{Introduction}

The purpose of peeling is to remove the skin tissue (peel) of raw fruits and vegetables; enhancing the appearance and taste of the finished product; achieving a clean, peeled surface, while minimizing peel losses [1]. Food industry applies the method of peeling in the case of potatoes, roots, tubers, and fruits [2]. There are several methods of peeling: mechanical peeling (knife peeling, abrasion peeling); peeling in a moist and warm medium (water, condensed water, alkaline solution); heating the peel by drying; carbonising or burning the peel; freezing and thawing of the vegetable surface [3]. Removal of inedible or undesirable parts of fruits and vegetables (e.g. leeks, artichokes) is called end cutting [4].

\section{Material and method}

Research was carried out at the vegetable processing plant of St. Andrew's Ltd., Kunpeszér. This plant has been cleaning and processing various vegetable plants with an automated production line for many years. Research was carried out from 01.08.2018. to 31.07.2019.

For the research a "ROPAI 1000" abrasive peeling machine, a "PANER SR" vegetable washer, and different kinds of vegetable cutter machines were used (Fig. 1.). These machines were manufactured by BanhiDesign s.r.o. (SK), and developed by Dolansgate Ltd. (CY) into a professionally automated version through a Delta PLC system. Water consumption was tested with a certified water meter. We measured the raw materials and peel losses with a certified industrial scale and recorded the data.

The purpose of this study is to compare the amount of green waste produced by peeling and processing of five different kinds of vegetables over a year, and to compare their monthly deterioration through the example of an operating vegetable processing plant. It was also aim to demonstrate the role of human and machine factors in the economic operation of a processing plant.

\footnotetext{
* Corresponding author. E-mail address: palkovics.andras@kvk.uni-neumann.hu
} 


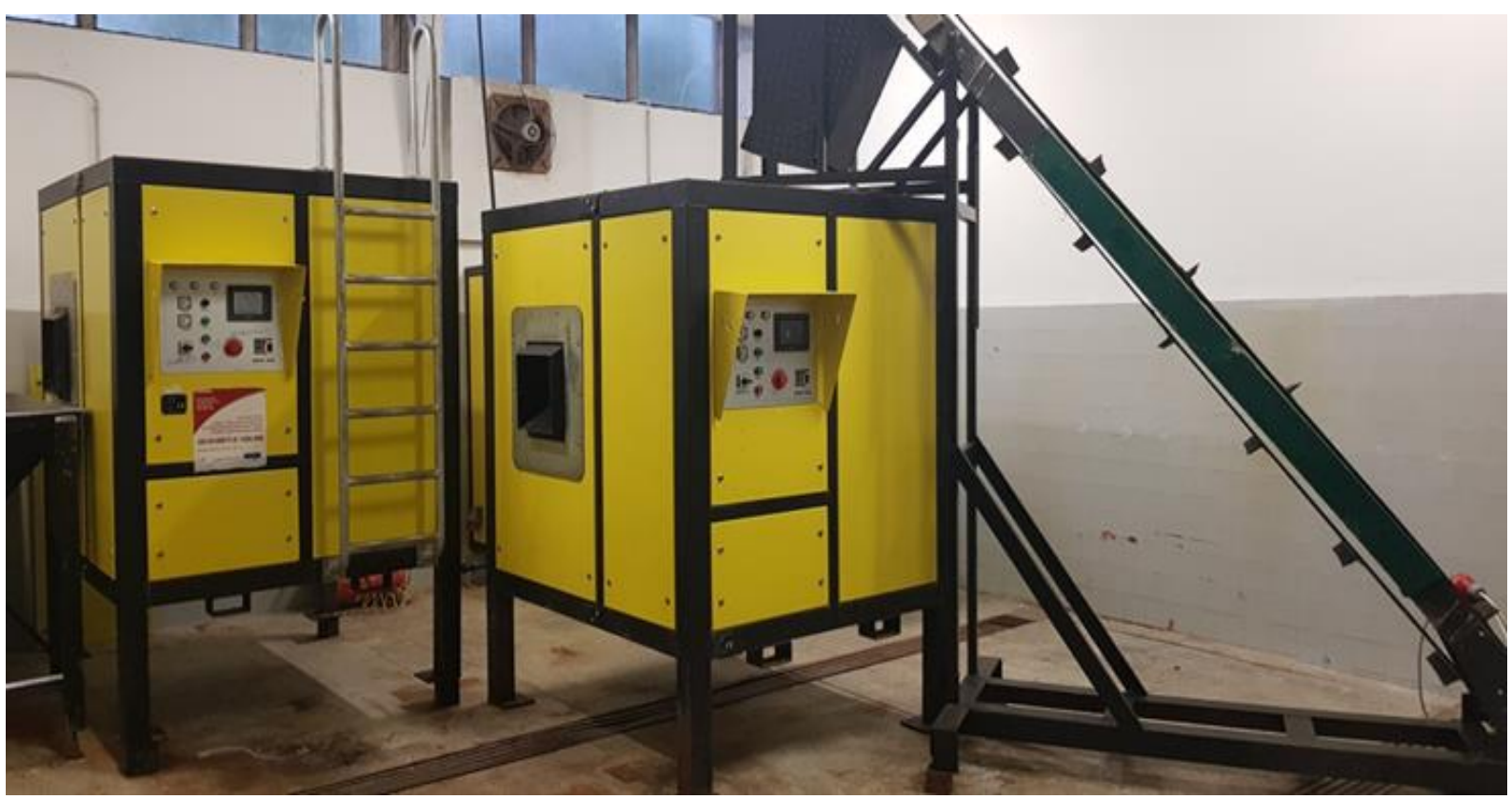

Figure 1. "ROPAI 1000" abrasive peeling machine

\section{Results}

Our results can be seen on Table 1.

Table 1.: Results

\begin{tabular}{|l|c|c|c|c|}
\hline \multicolumn{1}{|c|}{ Vegetable } & Raw material $\mathrm{kg})$ & Peeled material $(\mathrm{kg})$ & Peel loss $(\mathrm{kg})$ & $\%$ \\
\hline Celery & 2 & 1.35 & 0.65 & 32.5 \\
\hline Parsley root & 1.85 & 1.35 & 0.5 & 27 \\
\hline Carrot & 1.35 & 1.05 & 0.3 & 22.2 \\
\hline Potato & 7 & 5.5 & 1.5 & 21.4 \\
\hline Onion & 9.85 & 9.05 & 0.8 & 8.1 \\
\hline Potato & 160 & 125 & 35 & 21.9 \\
\hline Potato & 80 & 60.2 & 19.8 & 24.8 \\
\hline Onion & 12.95 & 11.9 & 1.05 & 8.1 \\
\hline Garlic & 0.4 & 0.3 & 0.1 & 25 \\
\hline Celery & 1.65 & 1.15 & 0.5 & 30.3 \\
\hline Parsley root & 1.852 & 1.4 & 0.452 & 24.4 \\
\hline Carrot & 5.3 & 4.15 & 1.15 & 21.7 \\
\hline Potato & 66 & 44 & 22 & 33.3 \\
\hline Onion & 11.5 & 10 & 1.5 & 13 \\
\hline Carrot & 8 & 6.25 & 1.75 & 21.9 \\
\hline Parsley root & 1.8 & 1.4 & 0.4 & 22.2 \\
\hline Celery & 1.8 & 1.3 & 0.5 & 27.8 \\
\hline Garlic & 0.4 & 0.3 & 0.1 & 25 \\
\hline Potato & 6.7 & 5.05 & 1.65 & 24.6 \\
\hline Onion & 11 & 10.2 & 0.8 & 7.3 \\
\hline & & & & \\
\hline & & & & \\
\hline
\end{tabular}




\begin{tabular}{|l|c|c|c|c|}
\hline Carrot & 8 & 6.05 & 1.95 & 24.4 \\
\hline Celery & 1.85 & 1.3 & 0.55 & 29.7 \\
\hline Parsley root & 1.8 & 1.35 & 0.45 & 25 \\
\hline Garlic & 0.4 & 0.35 & 0.05 & 12.5 \\
\hline Potato & 7.35 & 5.65 & 1.7 & 23.1 \\
\hline Onion & 12 & 11.1 & 0.9 & 7.5 \\
\hline Carrot & 5.9 & 4.65 & 1.25 & 21.2 \\
\hline Parsley root & 1.15 & 0.8 & 0.35 & 30.4 \\
\hline Celery & 1.65 & 1.15 & 0.5 & 30.3 \\
\hline Garlic & 0.4 & 0.35 & 0.05 & 12.5 \\
\hline Carrot & 5.21 & 4.28 & 0.93 & 17.9 \\
\hline Potato & 400 & 293 & 107 & 26.8 \\
\hline Onion & 10 & 9.25 & 0.75 & 7.5 \\
\hline Parsley root & 1.85 & 1.4 & 0.45 & 24.3 \\
\hline Celery & 1.75 & 1.3 & 0.45 & 25.7 \\
\hline Garlic & 0.35 & 0.3 & 0.05 & 14.3 \\
\hline Potato & 400 & 256 & 144 & 36 \\
\hline Potato & 260 & 167 & 93 & 35.8 \\
\hline Onion & 9.8 & 8.95 & 0.85 & 8.7 \\
\hline Carrot & 8 & 6 & 2 & 25 \\
\hline Garlic & 0.35 & 0.3 & 0.05 & 14.3 \\
\hline Celery & 1.7 & 1.2 & 0.5 & 29.4 \\
\hline Parsley root & 1.8 & 1.4 & 0.4 & 22.2 \\
\hline Potato & 420 & 287 & 133 & 31.7 \\
\hline Potato & 260 & 185 & 75 & 28.8 \\
\hline & & & & \\
\hline & & & 25 & \\
\hline
\end{tabular}

\section{Conclusions}

On the basis of our results, we can conclude that the cleaning loss of the tested vegetable plants are not uniform. Noteworthy is the low loss of onion, but it should be noted that the need for manual labor is much higher than in the case of the other vegetables. Celery has the highest cleaning loss because of the sectional surface of the tuber. In the case of potato, it is obvious that no increasing or decreasing tendencies can be determined as time passed (summer-autumn-winterspring), considering the amount of peel loss. The most important factors here are the storage conditions and the quantity of "sick" tubers. In the case of garlic, the Hungarian one is much larger than the Chinese import garlic, so it is more economical to clean, moreover the Chinese showed signs of frost in many cases.

We can conclude that through the right variety choice and product origin, the well-calculated operating time and its precise and continuous maintenance is essential for the economical operation of a vegetable processing plant. However, this continuous, tight schedule of technology can only be achieved with a professional automation system, so incorporating a computer-driven technological development is a good investment in a traditional vegetable processing plant. Against this background, the automation of a vegetable processing plant is only successful if we are aware of the processing characteristics of the types of vegetables to be processed. Therefore, it is very important to carry out proper studies and agricultural research before starting such an investment. 
In light of the above, it has great importance that not all vegetables can be economically cleaned, as in some cases (celery, onion) manual processing can greatly reduce the amount of green waste. Mechanical or manual processing is highly dependent on the quality of the product being processed and the shape of its surface, and in some cases, the storage or transport conditions.

\section{Acknowledgement}

We are grateful for the support of the research that carried out in the framework of the EFOP3.6.2-16-2017-00012 "Developing functional, healthy and safe food product chain model from field to table in a thematic research network". The project is funded by the Hungarian State and the European Union, co-financed by the European Social Fund, and is part of the Széchenyi 2020 program.

\section{References}

[1] Abrasive peeling of potatoes. [Online]. Available: https://www.sciencedirect.com/science/article/abs/pii/026087749400065H

[2] Peeling in food industry. [Online]. Available: http://wiki.zero-emissions.at/index.php/Peeling in food industry

[3] Processing, packaging solutions. [Online]. Available: https://proexfood.com/product/fruit-vegetable-packagingequipment/

[4] Automation in the food industry. [Online]. Available: https://www.foodprocessing.com/articles/2018/automation-inthe-food-industry 